\title{
Thermal Study of Blended Systems of Poly(methyl methacrylate) and Poly(vinyl acetate)
}

\author{
Shoji Ichinara*, Akihiko Komatsu**, and Toshio Hata \\ Department of Polymer Chemistry, Tokyo Institute of Technology, \\ Tokyo, Japan.
}

(Received March 5, 1971)

\begin{abstract}
Heats of solution of blended and non-blended systems of poly(methyl methacrylate) and poly(vinyl acetate) were measured at $28^{\circ} \mathrm{C}$. From the difference between them the heat of blending was estimated according to Hess's law. The absolute value for the blend prepared by freeze drying, which is thought to be molecularly mixed, was smaller than that for the blend, which shows partial phase separation. This unexpected result is explained by the differences of specific heat behaviour between the systems.
\end{abstract}
KEY WORDS Polymer Blend/Poly(methyl methacrylate)/Poly(vinyl acetate)/Heat of Solution/Specific Heat/Heat of Blending/Phase Separation/Compatibility/

It is well known that the entropy of mixing of polymer-polymer systems is so small in comparison with the enthalpy of mixing $\Delta H_{\mathrm{M}}$, that the free energy of mixing and the consequent compatibility is almost determined by $\Delta H_{\mathrm{M}}{ }^{1}$. In spite of the importance of $\Delta H_{\mathrm{M}}$, we cannot measure $\Delta H_{\mathrm{M}}$ of polymers directly. However, it can be estimated indirectly with the aid of Hess's law from the difference of heats of solution between homo-polymers and blended samples. ${ }^{2}$

In a previous work, ${ }^{3}$ we have shown that compatibility determined by $\Delta H_{\mathrm{M}}$ accords with that inferred by mechanical properties of blend film and that, for poly(methyl methacrylate) (PMMA) and poly(vinyl acetate) (PVAc), the values of $\Delta H_{\mathrm{M}}$ of the solvent cast blends vary with the conditions of preparation of the blended samples, e.g., the species of solvent used and the evaporation rate of the solvent. This behaviour is due to the different degrees of phase separation during the preparation of the blended films. In such cases, the measured heat of mixing should be called heat of blending because it reflects the degree of blending. These partially separated blends show more or less double dispersions in dynamic modules ${ }^{4}$ around

* Present address: Plastics Research Laboratory, Mitsubishi Petrochemical Co., Yokkaichi, Mie, Japan.

** Present address: Showa Denko Co., Tamagawa, Ohta-ku, Tokyo. the glass transition temperatures of the component polymers.

On the other hand, we can obtain a molecularly mixed blend of PMMA and PVAc by freeze drying, ${ }^{4}$ which shows only one dispersion like a random copolymer or a plasticized polymer. The present work is concerned with the heat of blending and other thermal properties of the blended sample of PMMA and PVAc prepared by freeze drying.

\section{EXPERIMENTAL}

\section{Materials}

Commercial poly(methyl methacrylate) and poly(vinyl acetate) were purified by precipitation from an acetone solution with $n$-hexane. The molecular weights of PMMA and PVAc determined by $[\eta]$ were $3.3 \times 10^{5}$ and $1.4 \times 10^{5}$ respectively. After being dried sufficiently, the weighed amounts of PMMA and PVAc were dissolved in benzene. The concentration of total polymers in solution was about ten per cent by weight. This solution was quenched to the Dry Ice-methanol temperature and then the frozen solution was sucked by a vacuum pump to sublimate the benzene. Completion of sublimation was confirmed by a Tesla's coil. The resulting powder was then pressed under vacuum and pressure of $4000 \mathrm{~kg} / \mathrm{cm}^{2}$ for several 
hours at room temperature. The appearance of the films obtained was transparent. These samples were used both for thermal and viscoelastic measurements. The results of the viscoelastic measurements have been reported in another paper. ${ }^{4}$

\section{Apparatus and Procedures}

The calorimeter employed for measurements of heats of solution of polymers and blended films was a conduction-type twin calorimeter based on the principle that Tian and Calvet first developed. A detailed description of this apparatus will be published elsewhere. ${ }^{5}$ The heat of solution was measured at $28^{\circ} \mathrm{C}$ dissolving about $0.3 \mathrm{~g}$ of sample to $100 \mathrm{cc}$ of benzene. As the concentration of final solution after dissolution was about 0.3 per cent, we can regard the obtained value as the heat of solution of the sample at infinite dilution. The standard deviation of the values of heats of solution measured by this apparatus is about $0.035 \mathrm{cal} / \mathrm{g}$ or 0.6 per cent.

According to Hess's law, the heat of blending $\Delta Q_{\mathrm{b} 1}$ (cal/g of blended sample) is calculated by

$$
\Delta Q_{\mathrm{b} 1}=\left(\Delta Q_{1}-\Delta Q_{2}\right) /(a+b)
$$

where $\Delta Q_{1}$ is the heat of solution for simultaneous dissolution of nonblended two polymers, $a \mathrm{~g}$ of polymer $\mathrm{A}$ and $b \mathrm{~g}$ of polymers $\mathrm{B}$ to $c \mathrm{~g}$ of solvent, and $\Delta Q_{2}$ is the heat of solution of $(a+$ $b) \mathrm{g}$ of the blended sample of $\mathrm{A}$ and $\mathrm{B}$ to $c \mathrm{~g}$ of solvent. Here we take the ratio $a /(a+b)$ to be equal to the weight fraction of $\mathrm{A}$ polymer in the blended sample, so that the final state after dissolution is the same in both measurements.

Specific heats of samples were measured by a differential scanning calorimeter model DSC-1 manufactured by the Perkin-Elmer Corporation. The calibration of this apparatus is described in another paper. ${ }^{5}$ The scanning speed and sensitivity setting used were $8^{\circ} \mathrm{C} / \mathrm{min}$ and $4 \mathrm{mcal} / \mathrm{sec}$ respectively. A synthetic sapphire was used as the calibration standard. In the present work, a scanning interval of $120^{\circ} \mathrm{C}$ was used. The scattering of the values of specific heats was usually within about $2 \%$. However, in the case of the blended samples, the error may be somewhat larger than this because there may be some uncertainty in the isothermal trace of DSC after scanning due to the exothermic phase separation which occurs above the glass transition temperature $T_{\mathrm{g}}$.

The glass transition temperatures of samples were determined by the volume-temperature relations measured by the usual dilatometer with a heating rate of $1^{\circ} \mathrm{C} / 2 \mathrm{~min}$.

\section{RESULTS}

The difference of volume-temperature curves between a freeze-dried sample and a solvent cast blend is that the former has only one inflection in the volume-temperature curve which is similar to that of random copolymer, while the latter has usually two inflections.

The glass transition temperatures of the freeze-dried samples are shown against the composition in Figure 1. Observed $T_{\mathrm{g}}$ 's are shown

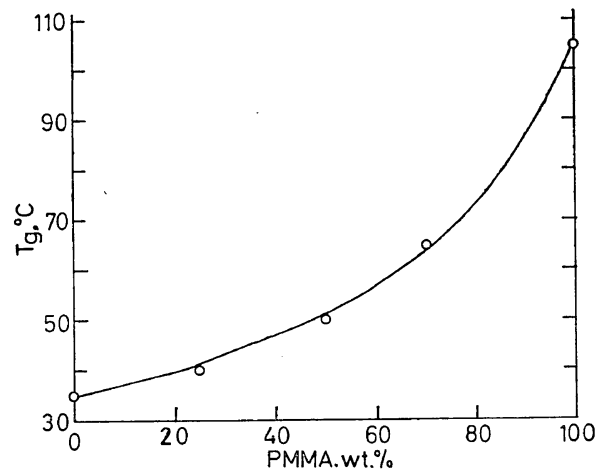

Figure 1. Glass transition temperature of samples plotted against the composition: $O$, observed values; solid line, calculated by eq 2 with $k=0.3$.

by open circles. The solid line is calculated by Kelly-Bueche's ${ }^{6}$ or Gordon-Taylor's ${ }^{7}$ equation

$$
T_{\mathrm{gb} 1}=\frac{\varphi T_{\mathrm{g} 1}+k(1-\varphi) T_{\mathrm{g} 2}}{\varphi+k(1-\varphi)}
$$

where $\varphi$ is the volume fraction of PVAc and $k$ is taken as 0.3 in the present case.

Figure 2 shows the results of the heat of blending at $28^{\circ} \mathrm{C}$. As the error of measurements of heats of solution is estimated to be about $0.035 \mathrm{cal} / \mathrm{g}$, that of the heats of blending is about $0.07 \mathrm{cal} / \mathrm{g}$. In the figure, the negative 


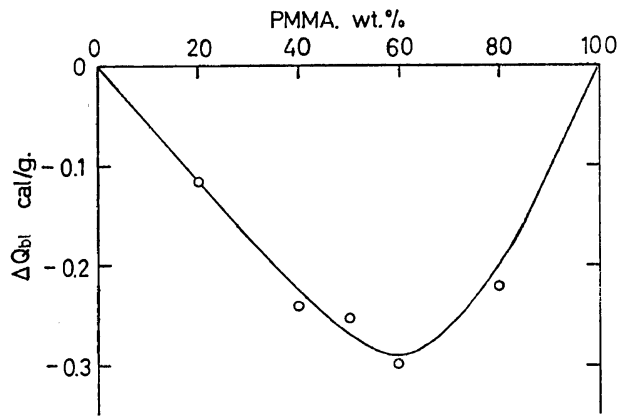

Figure 2. Heats of blending of blended samples made by the freeze-drying method plotted against composition.

sign means that PMMA and PVAc are not compatible with each other. $\Delta Q_{\mathrm{bl}}$ varies through a minimum near the molar ratio of monomer units of 50/50, where molecular contacts of PMMA and PVAc may become maximum.

Next, the freeze-dried sample of the $40-\%$ PMMA was kept, at $130^{\circ} \mathrm{C}$ for $85 \mathrm{~min}$, and then the heat of blending was measured at $28^{\circ} \mathrm{C}$ in the same way. $\Delta Q_{\mathrm{b} 1}$ obtained was -2.68 cal/g, which is curiously large in comparison with the value of the untreated sample, -0.24 cal/g. Because the heat-treatment causes the phase separation, consequently $\Delta Q_{\mathrm{b} 1}$ decreases in its absolute value. The reason for this will be discussed in the next section in connection with the change of specific heat.

The specific heats of blended samples of $40-\%$ PMMA are shown in Figure 3. Open circles are for the original blended sample prepared by freeze drying, solid circles are for the heattreated sample in the same conditions as described above, and the solid line is the calculation for a perfectly separated blend (see the next section). The specific heat of the blended sample before heat-treatment shows only one stepwise change. After heat-treatment, it shows a two step change corresponding to the glass transitions of PMMA and PVAc.

\section{DISCUSSION}

In Table I, the results of our previous work ${ }^{3}$

Table I. The heats of blending for solvent cast blends of 50:50 mixing of PMMA and $\mathrm{PVAc}^{\mathrm{a}}$ at $30^{\circ} \mathrm{C}^{3}$

\begin{tabular}{lcc}
\hline \multicolumn{1}{c}{ Solvent } & $\begin{array}{c}\text { Evaporation rate } \\
\text { of solvent }\end{array}$ & $\begin{array}{c}Q_{\mathrm{b} 1} \text {, at } 30^{\circ} \mathrm{C} \\
\mathrm{cal} / \mathrm{g}\end{array}$ \\
\hline Acetone & Rapid & -0.6 \\
$\begin{array}{l}\text { Acetone } \\
\text { Acetone } 90 \%+n \text {-hexane }\end{array}$ & Slow & $-0.5_{5}$ \\
$10 \%$ & Slow & -0.3 \\
\hline
\end{tabular}

a Molecular weights of PMMA and PVAc are $9.5 \times 10^{4}$ and $3.5 \times 10^{4}$ respectively.

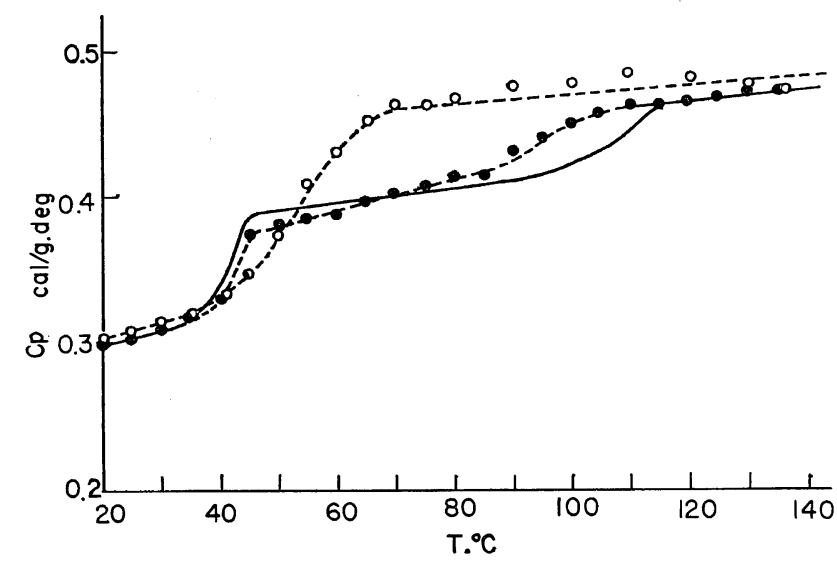

Figure 3. Specific heats of blended samples with composition of PMMA 40\% and PVAc 60\%: O, blended sample made by the freez-drying method; - , partially separated sample by heating the freeze-dried blend to $130^{\circ} \mathrm{C}$ and maintaining $85 \mathrm{~min}$; solid line, the perfectly separated blend, calculated with simple additivity from specific heats of homopolymers. 
for solvent-cast blends of PMMA and PVAc are summarized. Though the calorimeter used in the previous study was less precise than that in this study, we can say at least that the absolute value of $\Delta Q_{\mathrm{b} 1}$ of the freeze-dried blend is smaller than that of the solvent-cast blend. This fact is consistent with the result obtained in the present study, because the solvent-cast blend has more or less separated phases as in the case of the heat treated blend. This fact is unexpected and seems to be curious because the freezedried blend was obtained by the freeze-drying of a homogeneous solution and has only one $T_{\mathrm{g}}$ like random copolymer which is thought to be molecularly dispersed. ${ }^{4,6-8}$ However, if the changes of $C_{p}$ are taken into account, it can be understood as follows.

Heat of blending at temperature $T$ is defined as

$$
-\Delta Q_{\mathrm{b} 1}(T)=H_{\mathrm{b} 1}(T)-\left\{w H_{\mathrm{A}}(T)+(1-w) H_{\mathrm{B}}(T)\right\}
$$

where $H_{\mathrm{A}}, H_{\mathrm{B}}$, and $H_{\mathrm{b} 1}$ are enthalpies per gram of polymer $\mathrm{A}, \mathrm{B}$ and a blended system, and $w$ is the weight fraction of polymer A. By substitution of $H(T)=H\left(T_{0}\right)+\int_{T_{0}}^{T} C_{p} \mathrm{~d} T$ in each $H(T)$ in eq 3 , we obtain

$$
\begin{aligned}
-\Delta Q_{\mathrm{b} 1}(T) & =-\Delta Q_{\mathrm{b} 1}\left(T_{0}\right)+\int_{T_{0}}^{T} C_{p b 1} \mathrm{~d} T \\
& -\int_{T_{0}}^{T}\left\{w C_{p \mathrm{~A}}+(1-w) C_{p \mathrm{~B}}\right\} \mathrm{d} T
\end{aligned}
$$

where the term $\left\{w C_{p \mathrm{~A}}+(1-w) C_{p \mathrm{~B}}\right\}$ means a simple additivity of specific heats of component polymers, which can be calculated with the given values of $w, C_{p \mathrm{~A}}$, and $C_{p \mathrm{~B}}$ and is shown in Figure 3 by the solid curve. $C_{p \mathrm{~A}}$ and $C_{p \mathrm{~B}}$ used in the calculation were obtained by DSC measurements of homopolymers of PMMA and PVAc. Now let $T$ be the temperature higher than the glass transition temperatures of both components, e.g., $120^{\circ} \mathrm{C}$, and $T_{0}=28^{\circ} \mathrm{C}$, the temperature at which the measurement was made. Then $\Delta Q_{\mathrm{b} 1}(T)$ at $120^{\circ} \mathrm{C}$ is calculated with the values of $\Delta Q_{\mathrm{b} 1}\left(T_{0}\right)$ at $28^{\circ} \mathrm{C}$ and with the use of $C_{p}$ curves in Figure 3. The results are $-3.3 \pm 1.5 \mathrm{cal} / \mathrm{g}$ for the freeze-dried blend before heat-treatment and $-3.1 \pm 1.5 \mathrm{cal} / \mathrm{g}$ for heat- treated blend, which are resonable value at least in the order of magnitude, though the difference is small. Alternatively, $\Delta Q\left(T_{0}\right)$ is strongly dependent on the second term of the right-hand side of eq 4 . The values of this term are determined by the value of $C_{p b 1}$ and more dominantly by its inflection temperature, that is, $T_{\mathrm{gbl}}$. As seen in Figure 1 (and also in Figure 3), the glass transition temperature of the freeze-dried blend decreases remarkably, compared with the one calculated from the simple additivity. In the case of 40-\% PMMA blend, it becomes about $18^{\circ} \mathrm{C}$ smaller than the latter. This is the main reason for the small value of $\Delta Q_{\mathrm{bl}}\left(T_{0}\right)$ for the freeze-dried blend.

In conclusion, the heat of blending estimated from the heat of solution of a sample in the glassy state is strongly dependent on its blended state, while in the rubbery state it gives a rather plausible value. Considering the fact that in the freeze-dried blend, the component polymers are mixed to an extent that only one glass transition is shown, we can regard the value of $\Delta Q_{\mathrm{b} 1}=-3.3 \pm 1.5 \mathrm{cal} / \mathrm{g}$ at $120^{\circ} \mathrm{C}$ as the heat of mixing, neglecting the partial phase separation which will occur at higher temperatures in the process of DSC measurement.

\section{REFERENCES}

1. R. L. Scott, J. Chem. Phys., 17, 279, (1949).

2. G. V. Struminskii and G. L. Slonimskii, Zhur. Fiz. Khim., 30, 1941 (1956).

3. S. Ichihara and T. Hata, Kobunshi Kagaku (Chem. High Polymers, Japan), 26, 249, (1969).

4. S. Miyata and T. Hata, "Proceedings of the 5th International Congress on Rheology," University of Tokyo Press, Tokyo, 3, 71, (1970). See also S. Miyata, S. Ichihara, A. Komatsu, K. Suzuki, and T. Hata, Preprint, SPSJ 14th Symposium on Macromolecules, Fukuoko, 1967, II E 11 p 318.

5. S. Ichihara, A. Komatsu, and T. Hata, Polymer J., 2, 530 (1971).

6. F. N. Kelly and F. Bueche, J. Polym. Sci., 50, 549, (1961).

7. M. Gordon and J. S. Taylor, J. Appl. Chem., 2, 495, (1952).

8. E. A. DiMarzio and J. H. Gibbs, J. Polym. Sci., 40, 121, (1959). 